\title{
Optimal Design of Grid-Connected Solar Photovoltaic System Using Selective Particle Swarm Optimization
}

\author{
Habtemariam Aberie Kefale (D), Elias Mandefro Getie $\mathbb{D}$, and Kassaye Gizaw Eshetie \\ Bahir Dar University, Bahir Dar Institute of Technology, Bahir Dar, Ethiopia \\ Correspondence should be addressed to Habtemariam Aberie Kefale; habtemariam2727@gmail.com
}

Received 23 November 2020; Accepted 27 February 2021; Published 15 March 2021

Academic Editor: Regina De Fátima Peralta Muniz Moreira

Copyright (c) 2021 Habtemariam Aberie Kefale et al. This is an open access article distributed under the Creative Commons Attribution License, which permits unrestricted use, distribution, and reproduction in any medium, provided the original work is properly cited.

\begin{abstract}
The electricity distribution network in Ethiopia has the radial nature of network configuration. The interruption of power is due to overloading and failure of distribution lines due to external forces, like trees, animals, and wind. The failure of the radial distribution network brings blackout in the whole power system network as there is no alternative electricity supply. The renewable energy potential of Bahir Dar, Ethiopia, especially solar power is abundant and needs a mechanism to give a response for electricity demand in the country and city other than expecting from the national grid. The solar photovoltaic system interconnection in radial feeders may bring a solution for power interruption and network performance. The sizing and siting of the solar photovoltaic system in the Ethiopian radial distribution system required an optimization tool to obtain better distribution network parameter. The power loss minimization and voltage profile enhancement of the radial distribution network are the key objectives of this research. Selective particle swarm optimization (SPSO) is used to fix the size and site of installation for network capacity enhancement. A multiobjective optimization problem is formulated so as to meet different constraints to be optimized by the SPSO. Finally, the SPSO enables determining proper size and site of solar power installation and bringing better performance in the radial distribution network of Ethiopia.
\end{abstract}

\section{Introduction}

Electrical distribution systems are directly connected to end users. The infrastructure in distribution networks has a great role in power system reliability and quality. The radial type of the distribution system is common in most populated countries including Ethiopia. A radial system has only one power source for a number of customers as compared to a mesh system.

A short circuit, power failure, or a downed power line would interrupt power in the entire line which must be fixed before power can be restored. The following section explicitly presents the research motivation along with the extensive review of the previous related works and this research contribution with its organization.

1.1. Motivation and Incitement. The grid-connected PV system is preferable as compared to a standalone PV system due to the limited efficiency of energy conversion [1]. The effectiveness of grid-connected solar power strongly matters on solar irradiance of the site, load demand, ambient temperature, and other associated elements in the geographic area of installation. A key solution for radial distribution system performance improvement is identifying the optimal place for installation and size of solar PV which reduces the limitations of the existing distribution network.

The design of the PV system to interconnect with the radial distribution network using artificial intelligence techniques needs analysis and mathematical modeling of power system networks. The load flow analysis is used with the SPSO to determine the location and capacity of solar PV to interconnect with the Bahir Dar distribution network. Ethiopia is a country endowed with abundant energy resource potential, and the demand of electricity rapidly rises with the change of life in the country due to civilization. On-grid system integration of PV is important to boost the capacity of the network and increase system reliability by supporting the change of power demand in time change [2]. 


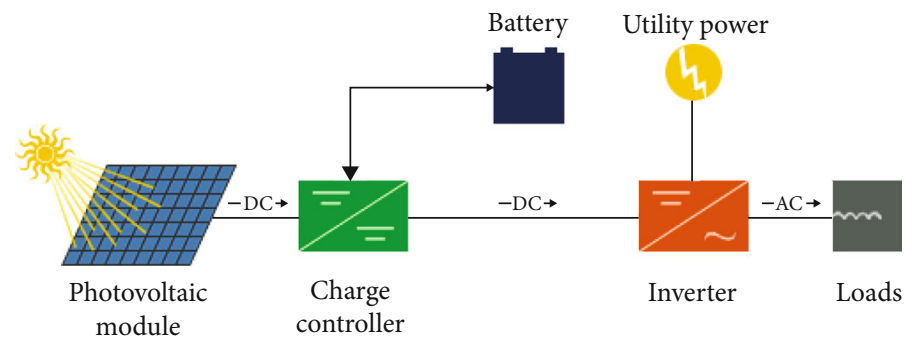

FIGURE 1: Schematic diagram of the on-grid photovoltaic system [8].

An on-grid solar power system interacts with the main grid. The main contribution of such system is that electricity can be drawn from the utility grid and when power is not available from the grid, the PV system can replace that power. These on-grid systems are designed with a battery or without battery storage. These systems consist of batteries, a charge controller, photovoltaic modules, and inverters to make the on-grid electricity system more reliable and to enable sustainable utility service for different loads [3]. The power electronic converters play a great role in interfacing the photovoltaic system with the grid in converting DC to $\mathrm{AC}$ and power conditioning. The point of connection and output power from the photovoltaic system for improving voltage profile and loss reduction were determined using selective particle swarm optimization using the selected method. The schematic diagram of the on-grid system to interconnect with radial feeders is given in Figure 1.

1.2. Literature Review. Ebeed et al. [4] in 2020 presented optimal reactive power dispatch focusing on assigning the most efficient and secure operating point of the electrical system. They have used a new natural-inspired algorithm commonly called the marine predators algorithm (MPA) considering various constraints such as load variation and generation limit. It has a significant contribution to boost the reliability of distribution systems as it optimally sizes and allocates renewable energy sources which are very intermittent and stochastic in nature.

Kamel et al. [5] also investigated the sizing and analysis of solar-wind-type distributed generation integration in a real distribution network incorporating some uncertainty. One of the most efficient algorithms the so-called Moth Flame Optimization (MFO) for power loss minimization and voltage profile enhancement is used in this research. The simulation results demonstrate that the proposed algorithm is effective to substantially reduce the line losses and improve the reliability as well.

Similarly, optimal reactive power dispatch with uncertainty in renewable energy resources in [6] is done with the help of an improved lightning attachment procedure optimizer. The proposed algorithm is very crucial to address the optimal reactive power dispatch (ORPD) problem using an improved version of the lightning attachment procedure optimization (LAPO), considering the uncertainties of the wind and solar RERs as well as load demand. The result was validated using the IEEE-30 bus system under deterministic and probabilistic conditions.

Phuangpornpitak and Tia [7] did the optimal placement of photovoltaic (PV) in the distribution system using self- organizing, hierarchical binary particle swarm optimization (SHBPSO). The paper uses SHBPSO to determine the optimal number and size of PV units in the distribution network. The active power supplied by the PV unit was determined using the proposed method, and the total power loss reduction was analyzed on a yearly basis. Only real power loss reduction is considered in the optimization of the distribution system during optimal placement and sizing of PV units.

Renuka et al. [8] investigated how to improve renewable energy penetration and power system stability using enhanced particle swarm optimization. The penetration level of renewable energy brings a challenge on small signal power system stability. The optimization tool enables fixing the penetration level of renewable energy by using a wind farm placement index for wind power and voltage and bus load absorption of solar power. In this paper, the design of renewable energy is not done using the optimization tool like generation capacity of renewable energy during penetration.

Alsadi [9] proposed photovoltaic optimization research status in a power system. The methods used to model, constraint criteria, and optimization tools used are reviewed during this research. The PV unit system has high potential, because the system is clean and environmentally friendly and has secure energy sources. The standalone and gridconnected photovoltaic generation impact on the power system network and its relation to demand response were studied. The size and location of photovoltaic generation were proposed to be done using optimization methods like the genetic algorithm and particle swarm optimization.

Phommixay et al. [10] reviewed cost optimization of the microgrid using the particle swarm optimization technique in different parameters. Optimization techniques are a key solution for operating and sizing of renewable energy for smooth operation of the power system. Optimal sizing of the microgrid is shown to be cost-effective, and using particle swarm for cost optimization is the appropriate method.

Getie et al. [2] did photovoltaic generation integration with radial feeders using the genetic algorithm and geographical information system. The size and point of penetration were determined using the genetic algorithm, and geographical information is used as data for the decision of solar power place of installation. This research only considers real power loss and voltage profile as the multiobjective function for photovoltaic integration.

1.3. Contribution and Paper Organization. In this research paper, a multiobjective optimization problem is considered 
TABLE 1: Bahir Dar City monthly average sunshine hour data.

\begin{tabular}{lllllllllllll}
\hline Months & Jan. & Feb. & Mar. & Apr. & May & Jun. & Jul. & Aug. & Sept. & Oct. & Nov. & Dec. \\
\hline 2010 & 2010 & 2010 & 2010 & 2010 & 2010 & 2010 & 2010 & 2010 & 2010 & 2010 & 2010 & 2010 \\
2012 & 2012 & 2012 & 2012 & 2012 & 2012 & 2012 & 2012 & 2012 & 2012 & 2012 & 2012 & 2012 \\
2013 & 2013 & 2013 & 2013 & 2013 & 2013 & 2013 & 2013 & 2013 & 2013 & 2013 & 2013 & 2013 \\
2014 & 2014 & 2014 & 2014 & 2014 & 2014 & 2014 & 2014 & 2014 & 2014 & 2014 & 2014 & 2014 \\
2015 & 2015 & 2015 & 2015 & 2015 & 2015 & 2015 & 2015 & 2015 & 2015 & 2015 & 2015 & 2015 \\
2016 & 2016 & 2016 & 2016 & 2016 & 2016 & 2016 & 2016 & 2016 & 2016 & 2016 & 2016 & 2016 \\
2017 & 2017 & 2017 & 2017 & 2017 & 2017 & 2017 & 2017 & 2017 & 2017 & 2017 & 2017 & 2017 \\
2018 & 2018 & 2018 & 2018 & 2018 & 2018 & 2018 & 2018 & 2018 & 2018 & 2018 & 2018 & 2018 \\
2019 & 2019 & 2019 & 2019 & 2019 & 2019 & 2019 & 2019 & 2019 & 2019 & 2019 & 2019 & 2019 \\
\hline
\end{tabular}

after reviewing different literatures done on the design of photovoltaic units to form a grid-connected or standalone microgrid in electric distribution networks to bring a solution for energy demand and security in Bahir Dar City, Ethiopia.

The paper firstly presents the resource potential assessment of solar energy in the selected area followed by overview of modified particle swarm optimization for power system applications. Then, it formulates the research problem the so-called problem formulation aimed to be solved. At the end, the simulation results with detailed discussion are deeply addressed.

\section{Resource Potential Assessment of Solar Energy}

Sunshine hour and solar radiance are the two fundamental factors for solar power plant efficiency $[11,12]$. The first factor can be defined as a climatological indicator, measuring duration of sunshine in a given period for a given location on earth, typically expressed as an average value over several years. In most deign cases, the sunshine hour is considered to be 5-6 hours per day.

The second factor is solar irradiance which is the power per unit area received from the sun in the form of electromagnetic radiation in the wavelength range of the measuring instrument.

The Ethiopian national metrology agency has recorded the sunshine hour of Bahir Dar City for ten consecutive years as shown in Table 1 .

Then, the solar insolation of the city is estimated using the Angstrom-Prescott (A-P) model.

$$
\begin{aligned}
H_{0}= & \frac{24}{\pi} G_{S C}\left(1+\cos \frac{360 n_{d}}{365}\right) \\
& *\left(\cos \varphi \cos \delta \sin \omega_{s}+\frac{\pi \omega_{s}}{180^{\circ}} \sin \varphi \sin \delta\right),
\end{aligned}
$$

where $\delta=23.45^{\circ} \sin \left(360^{\circ}\left(\left(284+n_{d}\right) / 365\right)\right), \cos \omega_{s}=-\tan$ $\varphi \tan \delta, H=H_{0}(a+(b n / N)), G_{\mathrm{sc}}$ is the solar constant $\left(1.367 \mathrm{~kW} / \mathrm{m}^{2}\right), \varphi$ is the latitude in degree, $\delta$ is the solar declination in degree, $\omega_{s}$ is the sunset hour angle in degree,

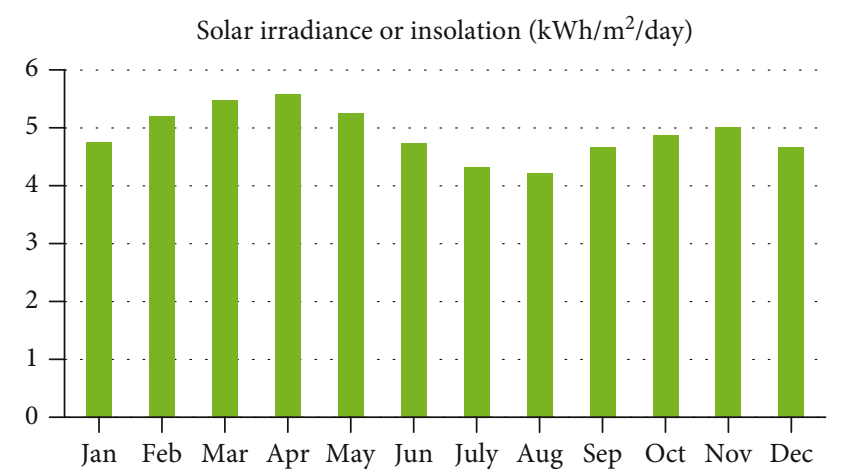

FIgURe 2: Ten-year monthly average solar irradiance of Bahir Dar City.

$n_{d}$ is the day of the year from January 1 to December 31 taking January 1st as $1, N$ is the monthly average of the maximum possible hours of sunshine, $n$ is the monthly average of daily hours of sunshine, $H_{0}$ is the monthly average of daily extraterrestrial solar radiation, $H$ is the monthly average of daily global solar radiation, and $a$ and $b$ are emperical cofficents.

Using the above relation, the solar radiation of Bahir Dar City is calculated and demonstrated in Figure 2. The obtained solar irradiation is in the estimated range between 4 and $6 \mathrm{kWh} / \mathrm{m}^{2} /$ day. The solar insolation data of Bahir Dar City indicates that it has much untouched potential resources for solar power plant even as compared to developed countries like Germany that uses more renewable energy resources.

\section{Modified Particle Swarm Optimization}

Particle swarm optimization (PSO) is a population-based stochastic optimization technique developed by Dr. Eberhat and Dr. Kennedy in 1995, inspired by social behavior of bird flocking or fish schooling $[11,12]$. PSO algorithms are suitable for finding the best feasible solution for an optimization problem by minimizing or maximizing a continuous and discrete function with respect to several subjects of equality and inequality constraints. 


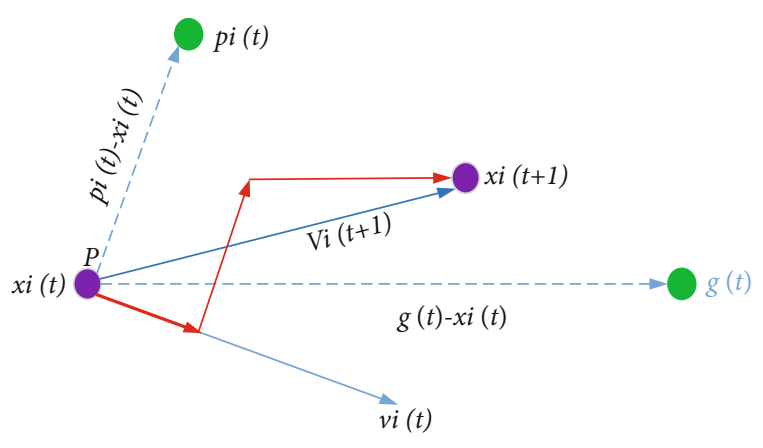

FIGURE 3: Graphical representation of PSO.

The problems particularly in power systems engineering are size and location determination of capacitors and DGs and/or optimal combination of tie-switches in the reconfiguration process. Details of PSO particularly for power systems application can be accessed in [13]. Therefore, this study focuses on the application of Modified Particle Swarm Optimization (MPSO) to search for a selected space for the best switching conditions which can result in minimum possible line losses and improve the voltage profile. The MPSO algorithm is presented as follows:

Each particle tries to modify its position using the following information as it is also graphically presented in Figure 3 [12].

(i) The particle current positions $\left(X_{i}\right)$

(ii) The particle current velocity $\left(V_{i}\right)$

(iii) The distance between the current position and personal best $\left(P_{\text {best }}\right)$

(iv) The distance between the current position and global best $\left(P_{\text {Gbest }}\right)$

The particle velocity is the sum of the inertia factor, the personal influence, and the social influence in the swarm, and each particle updates its velocity based on equation (1) [12].

$V_{i d}{ }^{t+1}=W * V_{i d}{ }^{t}+C_{1} * r_{1} *\left(P_{i d}{ }^{t}-X_{i d}{ }^{t}\right)+C_{2} * r_{2} *\left(P_{g b d}{ }^{t}-X_{i d}{ }^{t}\right)$,

$V_{i d}{ }^{t+1}=W * V_{i d}{ }^{t}+C_{1} * r_{1} *\left(P_{i d}^{t}-X_{i d}^{t}\right)+C_{2} * r_{2} *\left(P_{g b d}{ }^{t}-X_{i d}{ }^{t}\right)$.

In the conventional PSO, the search space is a real valued space or a set of selected standard values in the search space whereas the search space in the modified PSO is a set of 0's and 1's [14]. The modified PSO is accurately evaluated after conducting several iterations. The $i^{\text {th }}$ particle position at a dimension is selected to update

$$
\operatorname{Sigmoid}\left(V_{i d}{ }^{t+1}\right)=d n\left(\frac{1}{1+e^{V_{i d}{ }^{t+1}}}\right) \text {. }
$$

$$
\begin{aligned}
& \text { For } i=1,2 \cdots n \text { and } d=1,2 \cdots m, \\
& V_{i d}{ }^{t+1}= \begin{cases}S_{d 1}, & \text { if } \operatorname{sigmoid}\left(V_{i d}{ }^{t+1}\right)<1, \\
S_{d 2}, & \text { if } \operatorname{sigmoid}\left(V_{i d}{ }^{t+1}\right)<2, \\
S_{d 3}, & \text { if } \operatorname{sigmoid}\left(V_{i d}{ }^{t+1}\right)<3, \\
S_{d n}, & \text { if } \operatorname{sigmoid}\left(V_{i d}{ }^{t+1}\right)<d_{n},\end{cases}
\end{aligned}
$$

where $S_{d 1}, S_{d 2}, S_{d 3}$, and $S_{d n}$ are specified integral values in the dimension.

The particle velocity oscillation between the maximum and minimum values at dimension $d$ is governed by the following equations.

$$
V_{i d}{ }^{t+1}=\left\{\begin{array}{l}
\operatorname{rand} *\left(V_{i d}^{t+1}\right), \quad \text { if } V_{i d}{ }^{t+1}=V_{i d}{ }^{t}, \\
V_{i d}^{t+1}, \quad \text { otherwise. }
\end{array}\right.
$$

The design variables in optimal network reconfiguration are the number of available tie-switches in each loop. Thus, the following tie-switch representation is used in this research.

3.1. Particle Swarm Optimization Implementation Procedures. In the PSO algorithm, the population has $n$ -particles that represent candidate result. Each particle is an $N$-dimensional real valued vector where " $N$ " is the number of optimized parameters.

Step 1. Initialization: set the iteration counter $t=1$ that randomly generates an initial dimension of $n$-particles. The initial velocity of each particle is randomly generated for the calculation of the objective function, and $t_{\max }, W_{\min }$, $W_{\max }, c_{1}$, and $c_{2}$ are assigned then. In this step, the lower and higher bound of regional constraints is specified too.

Step 2. Set iteration count (for SPSO) iter $=1$.

Step 3. Maxiter > iter or tolerance.

Step 4. Objective function calculation.

Step 5. Upgrading of both the local minimum and the global minimum of particles.

Step 6. Velocity modification and update particle position.

\subsection{Algorithm for Particle Swarm Optimization}

\section{Problem Formulation}

In this research, one of Bahir Dar distribution feeders the so-called BATA feeder, shown in Figure 4, is considered for the optimal design of solar photovoltaic systems. The system has thirty-four (34) nodes and thirty-three (33) sectionalized lines or branches with $1.85 \mathrm{MW}$ and 1.25 MVAr active and reactive loads, respectively, during heavy load conditions (peak load). The end bus (34) is five kilometers from the main substation, and the system is radial in structure.

The line and load (bus) data of the case study distribution system (BATA feeder) are also presented in Table 2. 


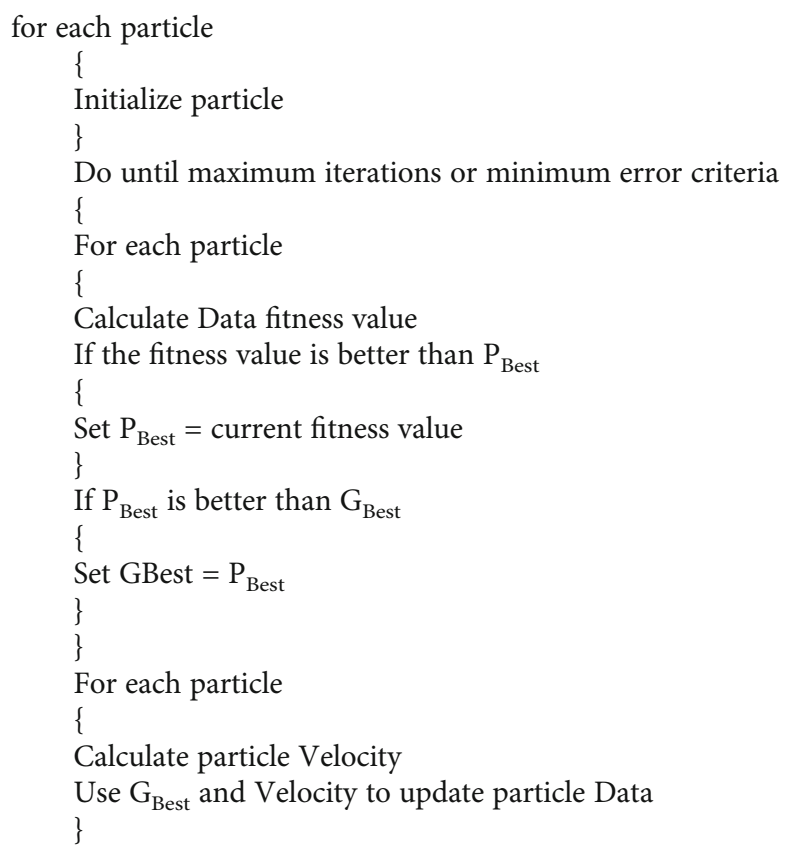

Algorithm 1

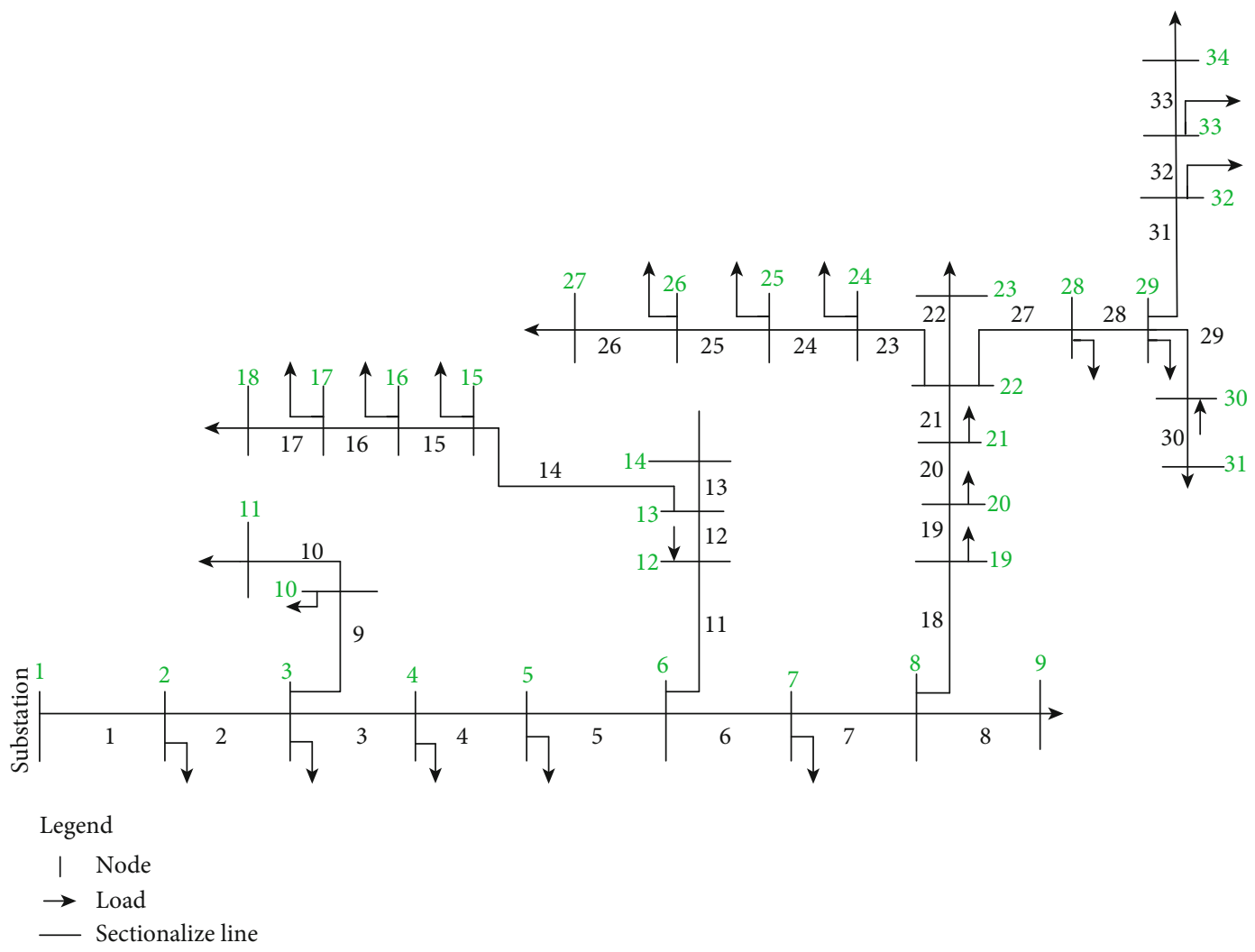

Figure 4: BATA feeder single-line diagram.

4.1. Power Loss Reduction. The radial distribution system configuration is widely used to distribute an electric energy to the end customer due to its simple structure and operating cost. However, this type of distribution network results in considerable power losses especially during heavy load condition since the end loads are very far from the substation, 
TABLE 2: Line and load data for the BATA feeder.

\begin{tabular}{|c|c|c|c|c|c|c|c|}
\hline $\begin{array}{l}\text { Sending node } \\
(i)\end{array}$ & $\begin{array}{l}\text { Receiving node } \\
(j)\end{array}$ & $\begin{array}{l}\text { Conductor } \\
\text { type }\end{array}$ & $\begin{array}{l}\text { Length } \\
(\mathrm{km})\end{array}$ & $\begin{array}{c}\text { Resistance } \\
(\Omega)\end{array}$ & $\begin{array}{c}\text { Reactance } \\
(\Omega)\end{array}$ & $\begin{array}{l}\text { Receiving end load } \\
(\mathrm{kW})\end{array}$ & $\begin{array}{c}\text { Receiving end load } \\
\text { (kVAr) }\end{array}$ \\
\hline 1 & 2 & AAC95 & 1.86 & 0.57381 & 0.399342 & 24.676 & 12.408 \\
\hline 2 & 3 & AAC95 & 0.291 & 0.0897735 & 0.0624777 & 9.960 & 6.690 \\
\hline 3 & 4 & AAC95 & 0.381 & 0.1175385 & 0.0818007 & 69.34 & 62.26 \\
\hline 4 & 5 & AAC95 & 0.679 & 0.2094715 & 0.1457813 & 25.770 & 10.590 \\
\hline 5 & 6 & AAC95 & 0.29 & 0.089465 & 0.062263 & 0.0000 & 0.0000 \\
\hline 6 & 7 & AAC95 & 1.106 & 0.341201 & 0.2374582 & 25.9750 & 15.8430 \\
\hline 7 & 8 & AAC95 & 0.555 & 0.1712175 & 0.1191585 & 0.0000 & 0.0000 \\
\hline 8 & 9 & AAC95 & 0.474 & 0.146229 & 0.1017678 & 48.000 & 25.800 \\
\hline 3 & 10 & AAC50 & 0.903 & 0.5225661 & 0.3938886 & 81.7100 & 71.110 \\
\hline 10 & 11 & AAC50 & 0.273 & 0.1579851 & 0.1190826 & 136.740 & 63.840 \\
\hline 6 & 12 & AAC25 & 0.499 & 0.589319 & 0.4164155 & 75.450 & 54.220 \\
\hline 12 & 13 & AAC95 & 0.711 & 0.2193435 & 0.1526517 & 0.0000 & 0.0000 \\
\hline 13 & 14 & AAC50 & 0.457 & 0.2644659 & 0.1993434 & 63.900 & 44.650 \\
\hline 13 & 15 & AAC50 & 1.276 & 0.7384212 & 0.5565912 & 80.400 & 52.800 \\
\hline 15 & 16 & AAC25 & 0.103 & 0.121643 & 0.0859535 & 41.980 & 21.800 \\
\hline 16 & 17 & AAC25 & 0.706 & 0.833786 & 0.589157 & 88.280 & 66.930 \\
\hline 17 & 18 & AAC50 & 0.347 & 0.2008089 & 0.1513614 & 5.080 & 3.0600 \\
\hline 8 & 19 & AAC50 & 0.245 & 0.1417815 & 0.106869 & 113.00 & 46.820 \\
\hline 19 & 20 & AAC95 & 1.123 & 0.3464455 & 0.2411081 & 85.070 & 62.200 \\
\hline 20 & 21 & AAC25 & 0.518 & 0.611758 & 0.432271 & 55.600 & 38.990 \\
\hline 21 & 22 & AAC50 & 0.5 & 0.28935 & 0.2181 & 0.0000 & 0.0000 \\
\hline 22 & 23 & AAC50 & 0.424 & 0.2453688 & 0.1849488 & 27.220 & 12.020 \\
\hline 22 & 24 & AAC50 & 0.28 & 0.162036 & 0.122136 & 28.040 & 12.590 \\
\hline 24 & 25 & AAC50 & 2.121 & 1.2274227 & 0.9251802 & 55.810 & 37.960 \\
\hline 25 & 26 & AAC25 & 0.188 & 0.222028 & 0.156886 & 74.600 & 55.230 \\
\hline 26 & 27 & AAC25 & 0.275 & 0.324775 & 0.2294875 & 46.520 & 24.540 \\
\hline 22 & 28 & AAC25 & 0.63 & 0.74403 & 0.525735 & 48.400 & 93.800 \\
\hline 28 & 29 & AAC50 & 0.328 & 0.1898136 & 0.1430736 & 9.3000 & 5.5000 \\
\hline 29 & 30 & AAC50 & 0.318 & 0.1840266 & 0.1387116 & 34.450 & 17.370 \\
\hline 30 & 31 & AAC50 & 0.197 & 0.1140039 & 0.0859314 & 25.780 & 48.740 \\
\hline 29 & 32 & AAC50 & 0.242 & 0.1400454 & 0.1055604 & 78.50 & 47.800 \\
\hline 32 & 33 & AAC50 & 0.379 & 0.2193273 & 0.1653198 & 98.000 & 66.000 \\
\hline 33 & 34 & AAC95 & 0.091 & 0.0280735 & 0.0195377 & 93.500 & 86.000 \\
\hline
\end{tabular}

and hence, the resistance of the lines increases with the length. Therefore, the aim of the optimal design of the gridconnected PV system is to decrease the active and reactive power losses by integrating the solar energy very close to the far end buses. When PV is integrated to the distribution system as depicted in Figure 5, the power loss equations derived above can be modified as

$$
\begin{aligned}
\Delta P_{\text {loss }}{ }^{\mathrm{DG}} & =\frac{R_{i}}{V_{i}{ }^{2}}\left(P_{G}{ }^{2}+Q_{G}{ }^{2}-2 P_{i} P_{G}-2 Q_{i} Q_{G}\right), \\
Q_{\mathrm{DG}, \mathrm{Loss}}(i, i+1) & =\frac{X_{i}}{V_{i}{ }^{2}}\left(P_{i}{ }^{2}+Q_{i}{ }^{2}\right)+\frac{X_{i}}{V_{i}{ }^{2}}\left(P_{G}{ }^{2}+Q_{G}{ }^{2}-2 P_{i} P_{G}-2 Q_{i} Q_{G}\right), \\
Q_{\mathrm{DG}, \mathrm{Loss}}(i, i+1) & =\frac{X_{i}}{V_{i}{ }^{2}}\left(P_{i}{ }^{2}+Q_{i}{ }^{2}\right)+\frac{X_{i}}{V_{i}{ }^{2}}\left(P_{G}{ }^{2}+Q_{G}{ }^{2}-2 P_{i} P_{G}-2 Q_{i} Q_{G}\right) .
\end{aligned}
$$

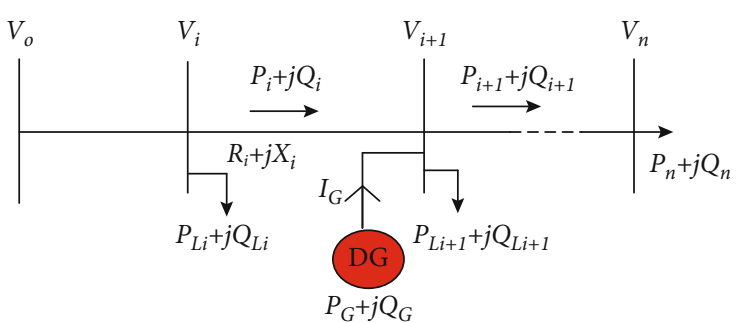

Figure 5: Modeling grid-tied PV.

The net power loss reduction in the system is

$$
\begin{aligned}
& \Delta P_{\text {loss }}{ }^{\mathrm{DG}}=\frac{R_{i}}{V_{i}^{2}}\left(P_{G}{ }^{2}+Q_{G}{ }^{2}-2 P_{i} P_{G}-2 Q_{i} Q_{G}\right), \\
& \Delta Q_{\text {loss }}{ }^{\mathrm{DG}}=\frac{X_{i}}{V_{i}{ }^{2}}\left(P_{G}{ }^{2}+Q_{G}{ }^{2}-2 P_{i} P_{G}-2 Q_{i} Q_{G}\right) .
\end{aligned}
$$




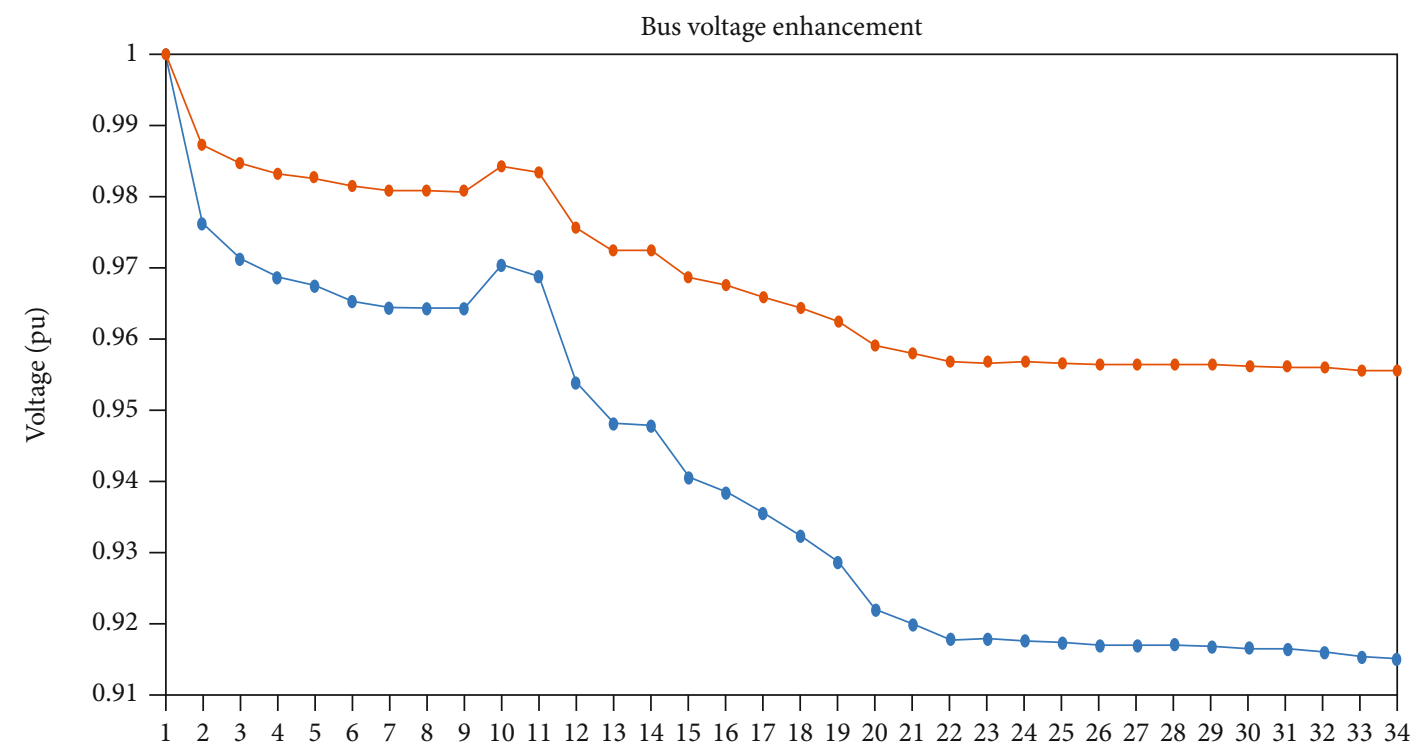

Bus

$\rightarrow$ Voltage profile before optimization

$\rightarrow$ Voltage profile after optimization

FIgURE 6: Voltage profile enhancement.

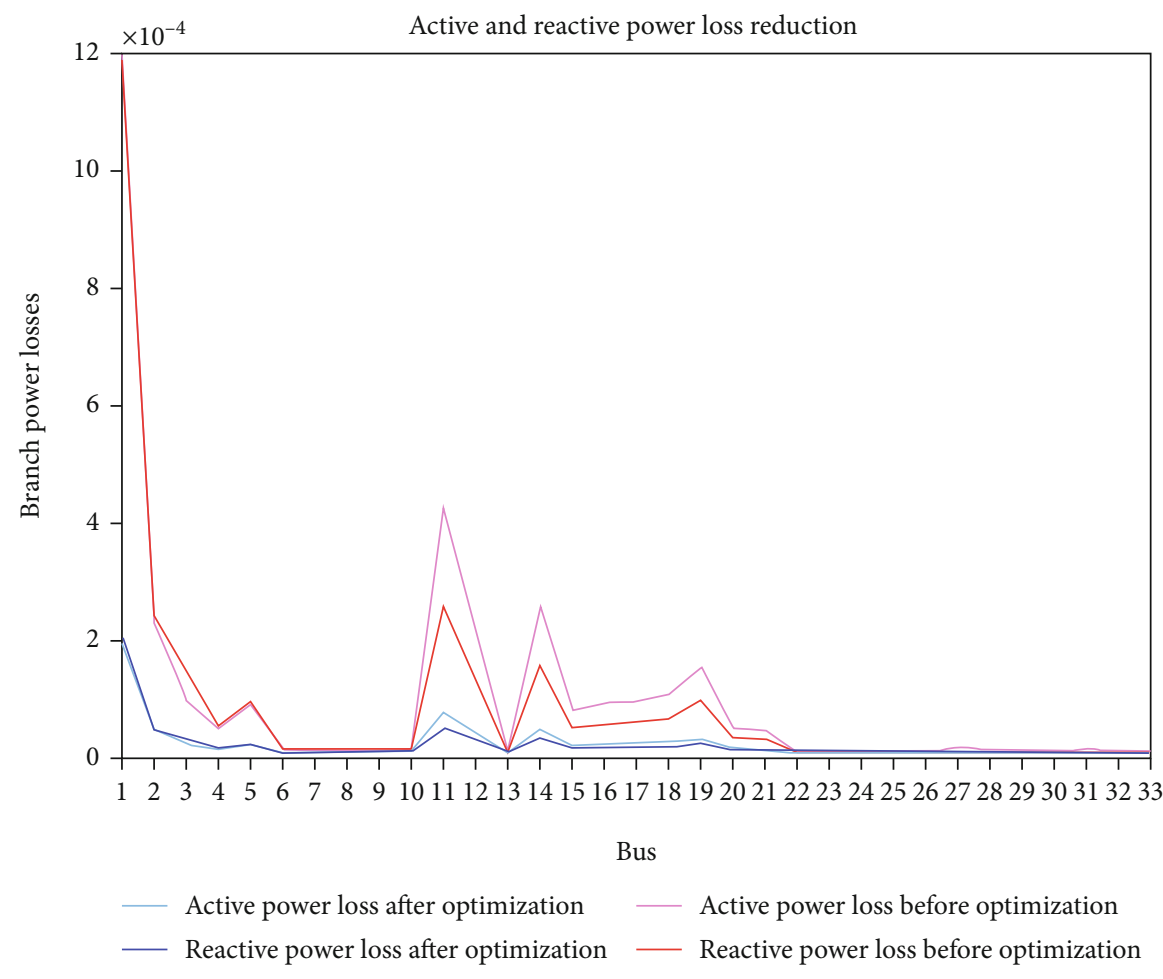

Figure 7: Branch power loss minimization.

4.2. Voltage Profile Improvement. The voltage profile of the majority nodes of a radial distribution system is poor usually below the minimum threshold value $(0.95 \mathrm{pu})[15,16]$. Solar $\mathrm{PV}$ integration is one of the most viable options to enhance these poor voltage magnitudes. However, it may lead to overvoltage problem if the integrated PV system is beyond the maximum limit, and the location is not identified using modern searching algorithms like particle swarm optimization and genetic algorithm. According to the IEEE recommendation, the voltage profile of all nodes must be maintained in the range of the minimum and the maximum value $\left(0.95 \leq V_{i} \leq 1.05\right)$. 
TABLE 3: Result summary.

\begin{tabular}{|c|c|c|c|c|c|c|c|}
\hline $\begin{array}{l}\text { Sending } \\
\text { node }(i)\end{array}$ & $\begin{array}{l}\text { Receiving } \\
\text { node }(j)\end{array}$ & $\begin{array}{l}\text { Sending bus } \\
\text { voltage before } \\
\text { optimization }\end{array}$ & $\begin{array}{l}\text { Sending bus } \\
\text { voltage after } \\
\text { optimization }\end{array}$ & $\begin{array}{c}\text { Base case active } \\
\text { power loss } \\
(\mathrm{kW})\end{array}$ & $\begin{array}{c}\text { Active power loss } \\
\text { after } \\
\text { optimization }\end{array}$ & $\begin{array}{c}\text { Base case reactive } \\
\text { power loss } \\
(\mathrm{kVAr})\end{array}$ & $\begin{array}{c}\text { Reactive power } \\
\text { loss after } \\
\text { optimization }\end{array}$ \\
\hline 1 & 2 & 1.0000 & 1 & 114.6105 & 74.496825 & 120.5035 & 78.327275 \\
\hline 2 & 3 & 0.9766 & 0.996132 & 22.4803 & 14.612195 & 23.6411 & 15.366715 \\
\hline 3 & 4 & 0.9715 & 0.99093 & 8.8539 & 5.755035 & 12.1647 & 7.907055 \\
\hline 4 & 5 & 0.9689 & 0.988278 & 4.0593 & 2.638545 & 4.2669 & 2.773485 \\
\hline 5 & 6 & 0.9678 & 0.987156 & 8.182 & 5.3183 & 8.6091 & 5.595915 \\
\hline 6 & 7 & 0.9655 & 0.98481 & 0.512 & 0.3328 & 0.5384 & 0.34996 \\
\hline 7 & 8 & 0.9647 & 0.983994 & 0.0132 & 0.00858 & 0.0139 & 0.009035 \\
\hline 8 & 9 & 0.9645 & 0.98379 & 0.00347 & 0.0022555 & 0.00365 & 0.0023725 \\
\hline 3 & 10 & 0.9645 & 0.98379 & 0.6425 & 0.417625 & 0.3854 & 0.25051 \\
\hline 10 & 11 & 0.9707 & 0.990114 & 0.8054 & 0.52351 & 0.4832 & 0.31408 \\
\hline 6 & 12 & 0.9691 & 0.988482 & 42.0612 & 27.33978 & 25.227 & 16.39755 \\
\hline 12 & 13 & 0.9541 & 0.973182 & 20.3041 & 13.197665 & 12.1897 & 7.923305 \\
\hline 13 & 14 & 0.9482 & 0.967164 & 0.0472 & 0.03068 & 0.0164 & 0.01066 \\
\hline 13 & 15 & 0.9480 & 0.96696 & 24.9607 & 24.9607 & 14.9764 & 9.73466 \\
\hline 15 & 16 & 0.9407 & 0.96506413 & 7.1499 & 4.647435 & 4.2864 & 2.78616 \\
\hline 16 & 17 & 0.9384 & 0.96270456 & 8.5109 & 5.532085 & 5.1065 & 3.319225 \\
\hline 17 & 18 & 0.9356 & 0.95983204 & 8.759 & 5.69335 & 5.2535 & 3.414775 \\
\hline 8 & 19 & 0.9325 & 0.95665175 & 14.6944 & 9.55136 & 8.8149 & 5.729685 \\
\hline 19 & 20 & 0.9287 & 0.95275333 & 9.9155 & 9.9155 & 5.9468 & 3.86542 \\
\hline 20 & 21 & 0.9220 & 0.95427 & 4.1484 & 2.69646 & 2.4443 & 1.588795 \\
\hline 21 & 22 & 0.9199 & 0.9520965 & 3.688 & 2.3972 & 2.2116 & 1.43754 \\
\hline 22 & 23 & 0.9178 & 0.9531353 & 0.00377 & 0.0024505 & 0.00226 & 0.001469 \\
\hline 22 & 24 & 0.9178 & 0.9531353 & 0.1277 & 0.083005 & 0.0766 & 0.04979 \\
\hline 24 & 25 & 0.9176 & 0.9529276 & 0.1825 & 0.118625 & 0.1096 & 0.07124 \\
\hline 25 & 26 & 0.9172 & 0.9525122 & 0.0715 & 0.046475 & 0.0429 & 0.027885 \\
\hline 26 & 27 & 0.9170 & 0.9523045 & 0.014 & 0.0091 & 0.00843 & 0.0054795 \\
\hline 22 & 28 & 0.9168 & 0.9520968 & 0.8669 & 0.563485 & 0.5195 & 0.337675 \\
\hline 28 & 29 & 0.9171 & 0.95240835 & 0.3715 & 0.241475 & 0.2229 & 0.144885 \\
\hline 29 & 30 & 0.9167 & 0.95199295 & 0.036 & 0.0234 & 0.0216 & 0.01404 \\
\hline 30 & 31 & 0.9165 & 0.95178525 & 0.0216 & 0.01404 & 0.0129 & 0.008385 \\
\hline 29 & 32 & 0.9164 & 0.9516814 & 0.6031 & 0.392015 & 0.3618 & 0.23517 \\
\hline 32 & 33 & 0.9159 & 0.95116215 & 0.3346 & 0.21749 & 0.1906 & 0.12389 \\
\hline 33 & 34 & 0.9153 & 0.95053905 & 0.0833 & 0.054145 & 0.05 & 0.0325 \\
\hline
\end{tabular}

As a result, the objective function can be formulated as shown below:

Maximize

$$
\begin{aligned}
& F=W_{1} * \Delta P_{\text {loss }}^{\text {DG }}+ W_{2} * \Delta Q_{\text {loss }}^{\text {DG }}-W_{3} * \sum_{i=1}^{N}\left(1-V_{i}\right)^{2} \\
& \text { Subject to }\left\{\begin{array}{l}
0.95 \leq V_{i} \leq 1.05 \\
I_{i j} \leq I_{i j}^{\max }, \\
P_{G} \leq P_{G}^{\max }, \\
Q_{G} \leq Q_{G}^{\max }, \\
W_{1}+W_{2}+W_{3}=1 .
\end{array}\right.
\end{aligned}
$$

where $W_{1}, W_{2}$, and $W_{3}$ are the weighting factors given to active and reactive power loss and voltage deviation reduction.

\section{Simulation Results and Discussion}

Firstly, the system without PV integration is simulated using a forward/backward load flow algorithm to determine the base case voltage profile and the corresponding active and reactive power losses. As shown in Figure 6, the voltage magnitude of all nodes except the first twelve buses is below the minimum threshold value which in turn exposes the far end customer to undervoltage problem. Likewise, the resistive loss before PV insertion is also considerable as depicted in Figure 7.

As shown in Figure 6 (red color), the voltage profile of all buses except the first bus is substantially improved after 
$75 \mathrm{~kW}$ DG is connected at the end bus. The minimum voltage before the installation of the PV was $0.9150 \mathrm{pu}$, but it is enhanced to 0.9654 pu due to the integration of optimal PV.

Similarly, the line active and reactive loss reduction when optimally designed PV is connected to bus 34 is presented in Figure 7. The active and reactive power losses are considerably minimized. In other words, the total active power loss reduction is $54.06 \%$ whereas the total reactive power loss reduction is $42.13 \%$.

In general, optimally designed photovoltaic system integration plays a vital role in enhancing the voltage profile of distribution systems particularly radial distribution network configuration. Furthermore, it is also used to substantially mitigate the line losses and hence to reduce the percentage power losses at the distribution level.

The simulation results such as base case voltage profile, improved voltage profile, and active and reactive power losses before and after the application of the proposed optimization are summarized in Table 3.

\section{Conclusion}

In this paper, optimal design of the grid-tied PV system is anticipated to substantially enhance the performance of the radial distribution system in terms of power losses and voltage profile. A modern optimization technique, namely, selective particle optimization algorithm, is used to determine the optimal size and location of the required photovoltaic. The resource feasibility of solar energy in Bahir Dar City is also conducted by collecting the sunshine hour data of ten consecutive years and converting it to solar insolation with the help of the Angstrom-Prescott method. Accordingly, the solar irradiation of the city is found between 4.5 and $5.5 \mathrm{kWh} / \mathrm{m}^{2} /$ day which indicates that PV integration is feasible. One of Bahir Dar distribution networks the so-called BATA feeder which has 34 nodes and $1.85 \mathrm{MW}$ and 1.25 MVAr peak load is selected as a case study in this research since it has the highest power loss and poor voltage profile as compared to other feeders existing in the city. The minimum voltage is enhanced from $0.9150 \mathrm{pu}$ to $0.9546 \mathrm{pu}$ whereas the percentage of active and reactive power losses is $54.06 \%$ and $42.13 \%$, respectively, when $75 \mathrm{~kW}$ solar PV is integrated to the selected feeder.

\section{Data Availability}

Data can be accessed via request to the authors.

\section{Conflicts of Interest}

The authors declare that they have no conflicts of interest.

\section{References}

[1] H. Mohammed Ridha, C. Gomes, H. Hizam, and M. Ahmadipour, "Optimal design of standalone photovoltaic system based on multi-objective particle swarm optimization: a case study of Malaysia," Processes, vol. 8, no. 1, p. 41, 2020.

[2] E. M. Getie, B. B. Gessesse, and T. G. Workneh, "Photovoltaic generation integration with radial feeders using GA and GIS," International Journal of Photoenergy, vol. 2020, 7 pages, 2020.
[3] P. Sritakaew, "On the reliability improvement of distribution systems using PV grid-connected systems," vol. 2014, 2007.

[4] M. Ebeed, A. Alhejji, S. Kamel, and F. Jurado, "Solving the optimal reactive power dispatch using marine predators algorithm considering the uncertainties in load and wind-solar generation systems," Energies, vol. 13, no. 17, p. 4316, 2020.

[5] S. Kamel, A. Ramadan, M. Ebeed, L. Nasrat, and M. H. Ahmed, "Sizing and evaluation analysis of hybrid solar-wind distributed generations in real distribution network considering the uncertainty," in 2019 International Conference on Computer, Control, Electrical, and Electronics Engineering (ICCCEEE), pp. 1-5, Khartoum, Sudan, 2019.

[6] M. Ebeed, A. Ali, M. I. Mosaad, and S. Kamel, “An improved lightning attachment procedure optimizer for optimal reactive power dispatch with uncertainty in renewable energy resources," IEEE Access, vol. 8, pp. 168721-168731, 2020.

[7] N. Phuangpornpitak and S. Tia, "Optimal photovoltaic placement by self-organizing hierarchical binary particle swarm optimization in distribution systems," Energy Procedia, vol. 89, pp. 69-77, 2016.

[8] T. K. Renuka, P. Reji, and S. Sreedharan, "An enhanced particle swarm optimization algorithm for improving the renewable energy penetration and small signal stability in power system," Renewables: Wind, Water, and Solar, vol. 5, no. 1, 2018.

[9] S. Alsadi and T. Khatib, "Photovoltaic Power Systems Optimization Research Status: a review of criteria, constrains, models, techniques, and software tools," Applied Sciences, vol. 8, no. 10, p. $1761,2018$.

[10] S. Phommixay, M. L. Doumbia, and D. Lupien St-Pierre, "Review on the cost optimization of microgrids via particle swarm optimization," International Journal of Energy and Environmental Engineering, vol. 11, no. 1, pp. 73-89, 2020.

[11] M. N. M. Nasir, N. M. Shahrin, Z. H. Bohari, M. F. Sulaima, and M. Y. Hassan, "A distribution network reconfiguration based on PSO considering DGs sizing and allocation evaluation for voltage profile improvement," in 2014 IEEE Student Conference on Research and Development, pp. 1-6, Penang, Malaysia, 2014.

[12] M. J. Tahir, I. A. Latiff, M. Alam, and M. S. Mazliham, "Network reconfiguration using modified particle swarm algorithm," in 2018 2nd International Conference on Smart Sensors and Application (ICSSA), pp. 1-5, Kuching, Malaysia, 2018.

[13] M. R. Alrashidi, M. F. Alhajri, A. K. Al-Othman, and K. M. ElNaggar, "Particle swarm optimization and its applications in power systems," Studies in Computational Intelligence, vol. 302, pp. 295-324, 2010.

[14] I. Hasan, M. Ab Ghani, and C. Gan, "Optimum distributed generation allocation using PSO in order to reduce losses and voltage improvement," 2014.

[15] B. Sookananta, W. Kuanprab, and S. Hanak, "Determination of the optimal location and sizing of distributed generation using particle swarm optimization," in ECTI-CON2010: The 2010 ECTI International Confernce on Electrical Engineering/Electronics, Computer, Telecommunications and Information Technology, pp. 818-822, Chiang Mai, Thailand, 2010.

[16] O. A. Saleh, M. Elshahed, and M. Elsayed, "Enhancement of radial distribution network with distributed generation and system reconfiguration," Journal of Electrical Systems, vol. 14, no. 3, pp. 36-50, 2018. 